\title{
Individual Calcium Syntillas Do Not Trigger Spontaneous Exocytosis from Nerve Terminals of the Neurohypophysis
}

\author{
James M. McNally, Valérie De Crescenzo, Kevin E. Fogarty, John V. Walsh, and José R. Lemos \\ Department of Physiology, University of Massachusetts Medical School, Worcester, Massachusetts 01665
}

Recently, highly localized $\mathrm{Ca}^{2+}$ release events, similar to $\mathrm{Ca}^{2+}$ sparks in muscle, have been observed in neuronal preparations. Specifically, in murine neurohypophysial terminals (NHT), these events, termed $\mathrm{Ca}^{2+}$ syntillas, emanate from a ryanodine-sensitive intracellular $\mathrm{Ca}^{2+}$ pool and increase in frequency with depolarization in the absence of $\mathrm{Ca}^{2+}$ influx. Despite such knowledge of the nature of these $\mathrm{Ca}^{2+}$ release events, their physiological role in this system has yet to be defined. Such localized $\mathrm{Ca}^{2+}$ release events, if they occur in the precise location of the final exocytotic event(s), may directly trigger exocytosis. However, directly addressing this hypothesis has not been possible, since no method capable of visualizing individual release events in these CNS terminals has been available. Here, we have adapted an amperometric method for studying vesicle fusion to this system which relies on loading the secretory granules with the false transmitter dopamine, thus allowing, for the first time, the recording of individual exocytotic events from peptidergic NHT. Simultaneous use of this technique along with high-speed $\mathrm{Ca}^{2+}$ imaging has enabled us to establish that spontaneous neuropeptide release and $\mathrm{Ca}^{2+}$ syntillas do not display any observable temporal or spatial correlation, confirming similar findings in chromaffin cells. Although these results indicate that syntillas do not play a direct role in eliciting spontaneous release, they do not rule out indirect modulatory effects of syntillas on secretion.

\section{Introduction}

$\mathrm{Ca}^{2+}$ serves as an integral intracellular messenger in many physiological processes, making the organization and control of intracellular $\mathrm{Ca}^{2+}\left(\left[\mathrm{Ca}^{2+}\right]_{\mathrm{i}}\right)$ a complex and important process. Neurotransmitter release is tightly coupled to elevations in $\left[\mathrm{Ca}^{2+}\right]_{\mathrm{i}}$ (Katz, 1969). Although the influx of $\mathrm{Ca}^{2+}$ through voltage-gated $\mathrm{Ca}^{2+}$ channels (VGCCs) is undoubtedly an important source of $\mathrm{Ca}^{2+}$ affecting exocytosis, recent findings suggest that intracellular stores provide an additional source of $\mathrm{Ca}^{2+}$ for this mechanism (Berridge, 2006).

In a number of neuronal preparations, highly localized intracellular $\mathrm{Ca}^{2+}$ release events have been observed (Emptage et al., 2001; Galante and Marty, 2003; De Crescenzo et al., 2004; Ouyang et al., 2005; Yao et al., 2006), similar to $\mathrm{Ca}^{2+}$ sparks of muscle. In nerve terminals of magnocellular neurons, or neurohypophysial terminals (NHT), these events, termed "syntillas," are observed in the absence of extracellular $\mathrm{Ca}^{2+}$ and are derived from a ryanodinesensitive store (De Crescenzo et al., 2004). The ryanodine receptors (RyRs) responsible for syntillas interact with dihydropyridine receptors, conferring a voltage dependence on these events through a process termed "voltage-induced $\mathrm{Ca}^{2+}$ release" (De Crescenzo

Received March 10, 2009; revised Aug. 26, 2009; accepted Sept. 10, 2009.

This study was financially supported by National Institutes of Health grants to J.R.L. and J.V.W. and a National Research Service Award Fellowship to J.M.M. We thank Dr. Hector Marrero for his comments on this manuscript.

Correspondence should be addressed to Dr. José R. Lemos, University of Massachusetts Medical School, 55 Lake Avenue North S4-137, Worcester, MA 01655. E-mail: Jose.Lemos@umassmed.edu.

J. M. McNally's present address: Department of Psychiatry, Harvard Medical School, VA Boston Healthcare System, Brockton, MA 02301.

DOI:10.1523/JNEUROSCI.1726-09.2009

Copyright $\odot 2009$ Society for Neuroscience ～0270-6474/09/2914120-07\$15.00/0 et al., 2006). This information notwithstanding, the physiological role for this phenomenon has yet to be conclusively determined.

$\mathrm{Ca}^{2+}$ release from intracellular stores enhances asynchronous neurotransmitter release in frog peripheral motor nerve terminals (Narita et al., 1998, 2000). A similar mechanism has been proposed to influence spontaneous multivesicular release via $\mathrm{Ca}^{2+}$ mobilization from a presynaptic ryanodine-sensitive store at inhibitory synapses onto cerebellar Purkinje cells (Llano et al., 2000). Such findings suggest that syntillas could play a role in secretion by providing another means of generating highly localized concentrations of $\mathrm{Ca}^{2+}$ sufficient to elicit exocytosis, distal to classical sites of $\mathrm{Ca}^{2+}$ influx.

Syntillas have also been observed in chromaffin cells, another secretory cell type (ZhuGe et al., 2006). Surprisingly, in this system, syntillas do not directly trigger spontaneous release, suggesting that the $\mathrm{Ca}^{2+}$ liberated must be localized to $\mathrm{Ca}^{2+}$ microdomains distinct from those involved in exocytosis. The amount of $\mathrm{Ca}^{2+}$ released during a syntilla is essentially identical in both chromaffin cells and NHT. However, these two systems express different subtypes of RyR. In NHT, syntilla frequency increases with depolarization in the absence of Ca influx. This appears to require type 1 RyR, which are absent in chromaffin cells whose syntillas lack voltage dependence. Such disparities lead to speculation that syntillas function differently in both systems. Previous studies in NHT have been unable to determine if syntillas are capable of driving spontaneous release, as no method was capable of directly correlating syntillas with individual exocytotic events.

To directly address this question, we used a false transmitter loading technique (Kim et al., 2000), allowing amperometric detection of individual exocytotic events in NHT. Concurrent use of this technique with fast $\mathrm{Ca}^{2+}$ imaging has allowed us to perform a spatio- 


\section{A Chromaffin Cell}

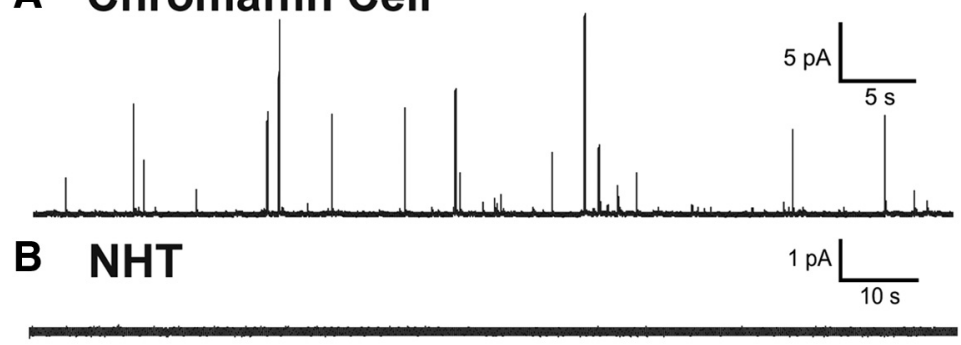

Before Loading

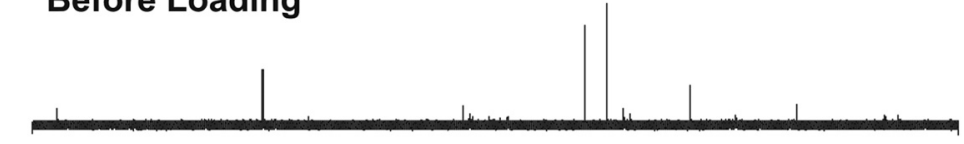

\section{After Loading}

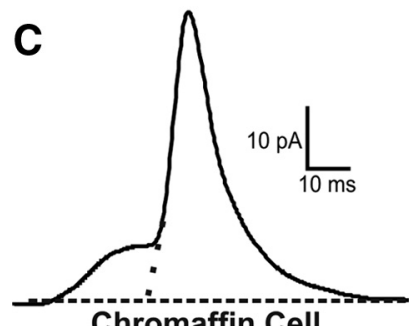

Chromaffin Cell

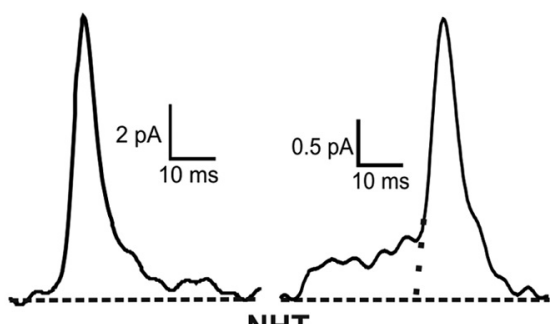

Figure 1. False transmitter loading of whole-cell patched NHT allows detection of spontaneous amperometric events similar to those seen in chromaffin cells. $A$, Amperometric recording from an isolated murine adrenal chromaffin cell showing spontaneous release events. $\boldsymbol{B}$, Amperometric recording performed immediately after whole-cell patch of an NHT voltage clamped at $-80 \mathrm{mV}$ shows that no amperometric activity is detectable in a non-DA-loaded terminal. After several minutes, allowing DA to dialyze into the terminal from the patch pipette, spontaneous amperometric release events can be observed. C, Amperometric events recorded from both chromaffin cells and false transmitter-loaded terminals appear very similar in nature, with the exception of their size. Prespike feet, a hallmark of amperometric recording of quantal release events, can be seen in a number of events (right) recorded from loaded NHTs.

Table 1. Comparison of amperometric events recorded from chromaffin cells to events from false transmitter-loaded NHT

\begin{tabular}{lcc}
\hline & Chromaffin cells & NHT \\
\hline Area (fC) & $138 \pm 232$ & $24 \pm 27$ \\
$\mathrm{~T}_{1 / 2}(\mathrm{~ms})$ & $20.7 \pm 14.2$ & $7.6 \pm 3.6$ \\
$I_{\max }(\mathrm{pA})$ & $6.8 \pm 0.2$ & $2.7 \pm 3.5$ \\
Rise time (pA/ms) & $1.3 \pm 2.9$ & $0.7 \pm 1.0$ \\
Decay (ms): $\tau_{1}$ & $30.0 \pm 47.7$ & $11.7 \pm 23.1$ \\
Decay (ms): $\tau_{2}$ & $88.3 \pm 116.7$ & $28.9 \pm 56.1$ \\
\hline
\end{tabular}

Data are the mean $\pm S D$ of pooled values of amperometric events recorded in NL solution. Chromaffin cells, $N$ (cells/terminals) $=4, n$ (events) $=512$. NHT, $N=32, n=1375$. Event decay fit with a double exponential.

temporal analysis of both syntillas and spontaneous exocytosis in NHT. Here, we report finding no evidence supporting a direct interaction between $\left[\mathrm{Ca}^{2+}\right]_{\mathrm{i}}$ released by syntillas and neuropeptide secretion, suggesting that as in chromaffin cells, NHT syntillas occur in $\mathrm{Ca}^{2+}$ microdomains separate from sites of exocytosis.

\section{Materials and Methods}

Isolation of murine NHT. NHT from adult Swiss Webster (greater than postnatal day 42) mice were prepared as described previously (Cazalis et al., 1987; Wang et al., 1999; De Crescenzo et al., 2004). Mice were quickly killed by cervical dislocation, in accordance with local Institutional Animal Care and Use Committee guidelines (protocol A-1135). After decapitation, neurohypophyses were harvested and dissociated via homogenization at $37^{\circ} \mathrm{C}$ in an isoosmotic solution of $270 \mathrm{mM}$ sucrose, 1 mM EGTA, 10 mM HEPES ( $\mathrm{pH} 7$ ). The dissociated terminals were then plated in the bottom of a perfusion chamber and perfused with Normal Locke's (NL) saline (in mM): $140 \mathrm{NaCl}, 5 \mathrm{KCl}, 10$ glucose, $1 \mathrm{MgCl}_{2}$, $2.2 \mathrm{CaCl}_{2}, 10$ HEPES, pH 7.3. For experiments in zero $\mathrm{Ca}^{2+} \mathrm{NL}, 200 \mu \mathrm{M}$
EGTA was substituted for $\mathrm{Ca}^{2+}$. NHT were identified by their smooth appearance, lack of nucleus, and high content of dark vesicles.

Electrophysiology. Dissociated murine NHT were patched and recorded from in the wholecell configuration using 5-10 $\mathrm{M} \Omega$ glass microelectrodes. A pipette solution containing (in mM) 135 Cs-gluconate, $2 \mathrm{MgCl}_{2}, 30$ HEPES, 15 dopamine (DA)-Cl, 4 Mg-ATP, 0.3 Na-GTP, $\mathrm{pH} 7.3$ was used for experiments examining amperometry alone or amperometry and membrane capacitance together.

Membrane capacitance was monitored using a software lock-in amplifier integrated with a computer-controlled patch-clamp amplifier (Pulse, EPC-10; HEKA) (Gillis, 2000). Changes in membrane capacitance, directly related to secretory activity, were followed using the "sine+dc" method (Lindau and Neher, 1988; Chen and Gillis, 2000; Gillis, 2000). To measure changes in membrane capacitance, a 15 $\mathrm{mV} 1500 \mathrm{~Hz}$ sine wave was superimposed onto the clamped DC holding potential $(-80 \mathrm{mV})$.

False transmitter loading. Loading NHT with the false transmitter DA was accomplished through the inclusion of DA (15 mM) in the pipette solutions used. NHT were patched in the whole-cell configuration and voltage clamped at a holding potential of either -80 $\mathrm{mV}$ (capacitance recordings) or $-60 \mathrm{mV}$ (calcium imaging experiments). DA was allowed to dialyze into the NHT, where it can then be trafficked into acidic compartments, including the large dense core vesicles (LDCVs) (Kim et al., 2000). This process generally required $\sim 5$ min for sufficient loading. While loading, a 5 $\mu \mathrm{m}$ diameter carbon fiber electrode (CFE), voltage clamped at $700 \mathrm{mV}$, was placed in close apposition to the plasma membrane of the terminal. When loaded LDCVs undergo exocytosis, DA released from NHT contacts the carbon fiber, where its subsequent oxidation results in a detectable current flow through the electrode. Successful loading was determined by the appearance of spontaneous amperometric events at a resting membrane potential of $-80 \mathrm{mV}$ (Fig. 1).

Analysis of amperometric spikes was performed using an Igor pro (Wavemetrics) macro, quanta analysis, written by Eugene Mosharov of David Sulzer's lab (available at www.sulzerlab.org). Amperometric events were detected using a peak threshold cutoff of $2.5 \times$ the root mean square of trace noise. Calculation of the total amperometric charge was performed using Origin 7 (Originlab). Amperometric charge was calculated by integrating baseline subtracted amperometric current traces.

Imaging of transient $\mathrm{Ca}^{2+}$ release events. Fluorescence imaging of intracellular $\mathrm{Ca}^{2+}$ transients was performed in the same manner as described previously (De Crescenzo et al., 2004, 2006; ZhuGe et al., 2006). NHT were whole-cell patched using a pipette solution of (mM) $135 \mathrm{KCl}$, $2 \mathrm{MgCl}_{2}$, 30 HEPES, $4 \mathrm{Mg}$-ATP, $0.3 \mathrm{Na}$-GTP, $0.05 \mathrm{~K}_{5}$-fluo3, and $15 \mathrm{DA}$, $\mathrm{pH}$ 7.2. High-speed $\mathrm{Ca}^{2+}$ imaging was performed using a custom-built inverted wide-field microscope equipped with a Nikon $100 \times(1.3 \mathrm{NA})$ oil-immersion objective and high-resolution charge-coupled device camera, providing $133 \mathrm{~nm}$ of specimen per image pixel. Imaging was performed at a rate of $50 \mathrm{~Hz}(10 \mathrm{~ms}$ exposure) for $4 \mathrm{~s}$ at a time. The total amount of $\mathrm{Ca}^{2+}$ released per syntilla was quantified by measuring its "signal mass" as described previously (Sun et al., 1998; ZhuGe et al., 2000; De Crescenzo et al., 2004).

\section{Results}

\section{DA loading of NHTs}

RyR agonists have been shown to elicit neuropeptide release from populations of isolated NHT (Jin et al., 2007). Although these 
results are quite intriguing, standard population release assays do not provide either the temporal or spatial resolution necessary for direct comparison of neuropeptide release with syntillas. Accomplishing this goal required the development of a means by which quantal exocytotic events could be observed on a time scale consistent with what is used to record syntillas. Electrochemical detection techniques such as amperometry have been successfully used for this purpose in other systems. However, as NHT do not package readily oxidizable material into their large dense core granules, it is not feasible to use this technique to monitor endogenous peptide release.

Previous work has shown that cultured secretory cells are capable of packaging and releasing exogenous transmitters, provided there is a sufficiently high concentration of that transmitter present in the cytosol (Zhou and Misler, 1996; Kim et al., 2000). To develop a practical means of accomplishing this in NHTs, the exogenous transmitter DA was loaded by its addition into the whole-cell patch-pipette solution. This method has been previously used to allow differentiated neurons to secrete false transmitters (Dan et al., 1994).

As displayed in Figure $1 B$, no amperometric activity was observed in NHTs before DA loading. However, several minutes after whole-cell break-in, allowing DA to dialyze into the terminal cytosol, the same terminal shows numerous spontaneous current spikes. These events appear similar to amperometric release events recorded under similar conditions from chromaffin cells, a system that releases a native oxidizable transmitter (compare to Fig. 1A).

Close examination of NHT amperometric events (Table 1; Fig. 1C) shows that they possess similar kinetic parameters to those observed in chromaffin cells, with the exception of their size. This is not surprising, as one would not expect that the amount of false transmitter loaded into a vesicle could come close to approaching the concentration present in a system where amperometry can be used under native conditions. Additionally, the amperometric events observed were quite variable in amplitude (see $I_{\max }$, Table 1). This is consistent with the findings of previous false transmitter-loading studies and is predicted to be attributable to considerable diversity in vesicle loading (Kim et al., 2000).

Interestingly, small current steps preceded some of the amperometric spikes observed in false transmitter-loaded NHT, which appear similar in nature to the prespike "feet" observed during native catecholamine release events from chromaffin cells (Fig. 1C). A prespike foot is believed to correspond to the slow release of transmitter through a fusion pore before pore widening and complete collapse of the vesicle into the plasma membrane
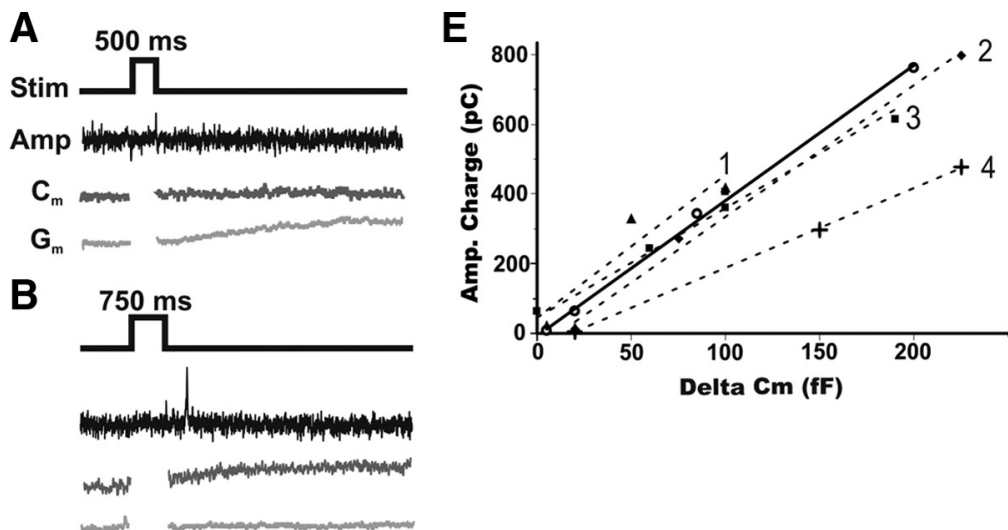

Figure 2. Amperometric activity in false transmitter-loaded terminals correlates with exocytotic activity observed using membrane capacitance recording. $\boldsymbol{A}-\boldsymbol{D}$, Simultaneous amperometric (Amp) and membrane capacitance $\left(C_{\mathrm{m}}\right)$ recordings taken from a representative false transmitter-loaded terminal. The terminal was given a series of depolarizing stimuli $(-80$ to $0 \mathrm{mV})$ increasing in duration from $\boldsymbol{A}$ to $\boldsymbol{D}$. Both the amount of amperometric activity and the evoked change in membrane capacitance increased e capacitance $\left(\right.$ delta $\left.C_{m}\right)$ reveals a strong linear correlation. Here, the total change in capacitance was measured as the presentative of the correlation seen between amperometric and membrane capacitance recordings taken from a number of individual minals (solid black line; $r^{2}=0.99$ ). Dashed lines $1-4$ show four additional examples of terminals where at least three different duration depolarizing stimuli where applied. The comparative amperometric and capacitance data (triangles, diamonds, squares, cross, respectively) as well as the linear fit $\left(r^{2}=0.89,0.97,0.99,0.99\right.$, respectively) are plotted.

(Chow et al., 1992). Such prespike feet have also been described in other false transmitter-loaded systems (Zhou and Misler, 1996). The appearance of this hallmark of native amperometric release recorded from false transmitter-loaded terminals is further evidence that these amperometric events represent exocytotic release.

\section{Comparison of amperometry with capacitance recording}

To ensure that events detected via amperometry do in fact represent exocytotic release, membrane capacitance recordings were performed in concert with amperometric detection. When depolarizing stimuli of different durations were applied to an individual terminal (Fig. $2 A-D$ ), the amount of amperometric activity 


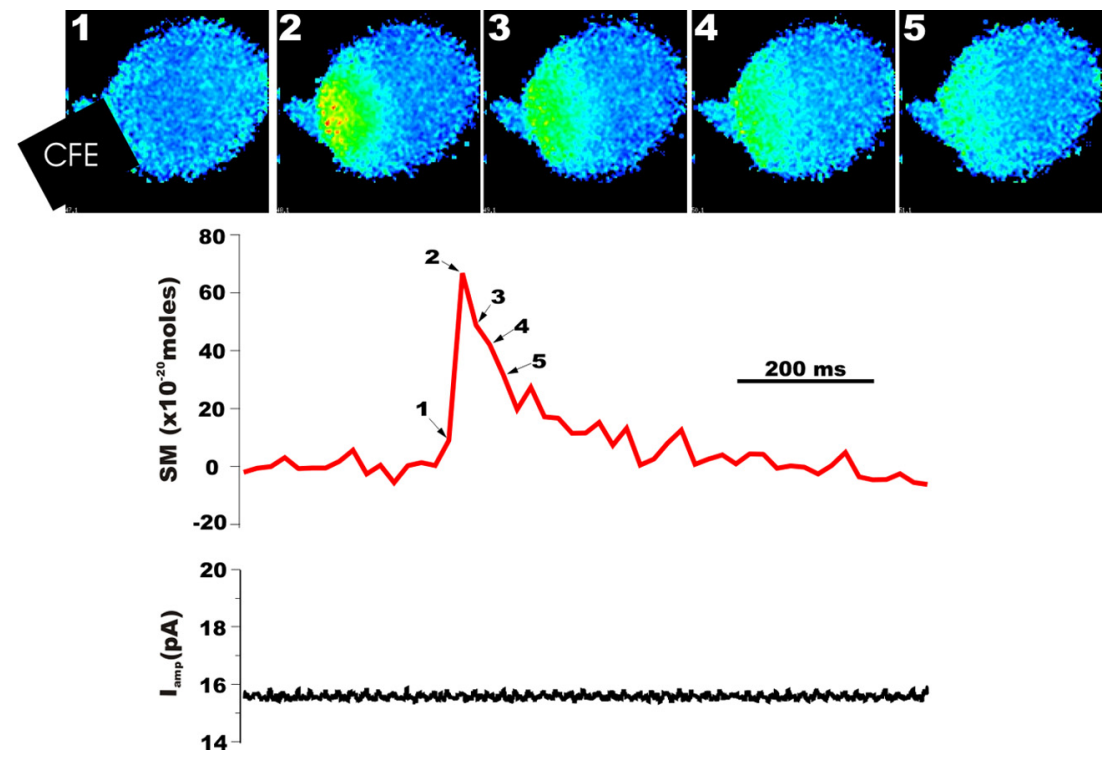

Figure 3. Calcium syntillas do not trigger spontaneous release events. In false transmitter-loaded terminals, voltage clamped at $-60 \mathrm{mV}, \mathrm{Ca}^{2+}$ imaging of syntillas and amperometric recording of exocytotic events can be performed simultaneously. Top, Leftmost image shows positioning of the CFE relative to a whole-cell patched terminal loaded with the false transmitter, dopamine, and the $\mathrm{Ca}^{2+}$ indicator dye, fluo-3. Images $1-5$ represent the image frames taken immediately before the appearance of the syntilla and the following four frames, respectively. The syntilla is observed to occur precisely in the area where the CFE is positioned. Bottom, Concurrent records of fluorescence in the region of the terminal where the syntilla occurs (red trace) and amperometric current (black trace) show that there are no amperometric events immediately correlated with this syntilla, despite the fact that this syntilla represents the release of $\sim 400,000 \mathrm{Ca}^{2+}$ ions $\left[\right.$ signal mass (SM) $=66.4 \times 10^{-20} \mathrm{~mol}$ $\left.\mathrm{Ca}^{2+}\right]$ in the precise area where the CFE is located. The numbers on the fluorescence trace correspond to the numbered images above.

increased as the duration of the depolarizing stimulus increased. This response mirrored that seen using membrane capacitance to assay secretory activity. Plotting the magnitude of the change in membrane capacitance elicited by a stimulus (synchronous plus asynchronous change) versus the total amount of amperometric activity (amperometric charge) over the same time span shows a strong linear correlation between these two measures of release in false transmitter-loaded terminals (Fig. 2 E). Slight variations in the slope of this correlation were observed from terminal to terminal possibly representing slight differences in false transmitter-loading efficiency or differing placement of the CFE altering the percentage of total exocytosis detected amperometrically. Interestingly, with longer duration stimuli, asynchronous exocytotic activity was apparent in both the amperometric and membrane capacitance records (Fig. 2C,D). In such instances, the relationship between these two separate measures of exocytotic activity was clearly evident. As amperometric activity subsided, the increase in membrane capacitance also stopped.

\section{Simultaneous recording of syntillas and spontaneous} release events

Spatiotemporal modeling of syntillas demonstrates that the average syntilla is capable of raising intracellular $\mathrm{Ca}^{2+}$ to supramicromolar concentrations for tens of milliseconds hundreds of nanometers away from the site of $\mathrm{Ca}^{2+}$ release (De Crescenzo et al., 2004). In NHT, a free $\mathrm{Ca}^{2+}$ concentration of $10 \mu \mathrm{M}$ is thought to be maximal for triggering exocytotic release (Lee et al., 1992). Therefore, if a syntilla were to occur in close proximity to an exocytotic release site, it could conceivably drive the exocytotic event.

A simple comparison of the rates of spontaneous release and syntillas provides a simple means of looking at the relationship between these two events. We found that in the presence of extracellular $\mathrm{Ca}^{2+}$ the rate of basal release, as observed with amperometry, is approximately five events per minute. Since amperometry shows $\sim 10 \%$ of the secretory activity for a terminal, the rate of basal release for the entire terminal would be $\sim 50$ release events per minute. This is approximately twice the frequency of syntillas in the presence of extracellular $\mathrm{Ca}^{2+}, \sim 27$ per minute (De Crescenzo et al., 2004). Considering the number of assumptions required for this comparison, this twofold discrepancy is not compelling enough to rule out the idea that these two events are related.

To directly test this relationship in a more straightforward manner, a combination of high-speed $\mathrm{Ca}^{2+}$ imaging and amperometric detection of release was used. For these experiments, NHT were whole-cell patched and voltage-clamped at $-60 \mathrm{mV}$. This holding potential had been observed in previous studies to increase syntilla frequency while not significantly altering bulk intracellular $\left[\mathrm{Ca}^{2+}\right]$ (De Crescenzo et al., 2004), thus increasing the likelihood of observing any possible correlation between syntillas and spontaneous exocytotic events.

We observed a large number of syntillas in false transmitter-loaded terminals in $\mathrm{Ca}^{2+}$-free media (99 syntillas observed from 19 different terminals); of these syntillas, 19 occurred precisely at the region of the terminal membrane where the CFE was positioned, within $2.5 \mu \mathrm{m}$ of the center of the electrode. Syntillas proximal to CFE were recorded from 10 different NHT. The magnitude of each of these syntillas was determined using the signal mass approach (Sun et al., 1998; ZhuGe et al., 2000), which yields the amount of $\mathrm{Ca}^{2+}$ ions released (see Fig. 4).

The rate at which exocytosis occurs depends on the kinetics of the fusion machinery, which for large dense core granules has been determined to be on the order of a few milliseconds (Heinemann et al., 1994). In addition, the detection of exocytotic release with amperometry results in a delay of few milliseconds after granule fusion (Chow et al., 1996). Given these rates, if the $\mathrm{Ca}^{2+}$ released by a syntilla was directly responsible for eliciting exocytosis, one would expect an exocytotic release event within tens of milliseconds after appearance of the syntilla. However, in no case did we see any evidence of such an immediate correlation between the observed syntilla and release, no matter what the magnitude of the syntilla (Figs. 3, 4A).

Syntillas could only be recorded in $4 \mathrm{~s}$ epochs at $50 \mathrm{~Hz}$, leaving open the possibility that an association between syntillas and spontaneous release events beyond this time span was going unnoticed. To address this possibility, longer duration amperometric traces were recorded, allowing us to monitor spontaneous exocytotic activity well before and after 14 of the recorded syntillas occurring at the CFE. This allowed us to determine the amount of time between the syntillas and the next observed spontaneous release event. Still, no discernible association between syntillas and exocytosis was observed (Fig. $4 B$ ). Spontaneous release events were observed, on average, $30.89 \pm 9.82 \mathrm{~s}$ after these syntillas, with the closest occurring after $1.51 \mathrm{~s}$. 


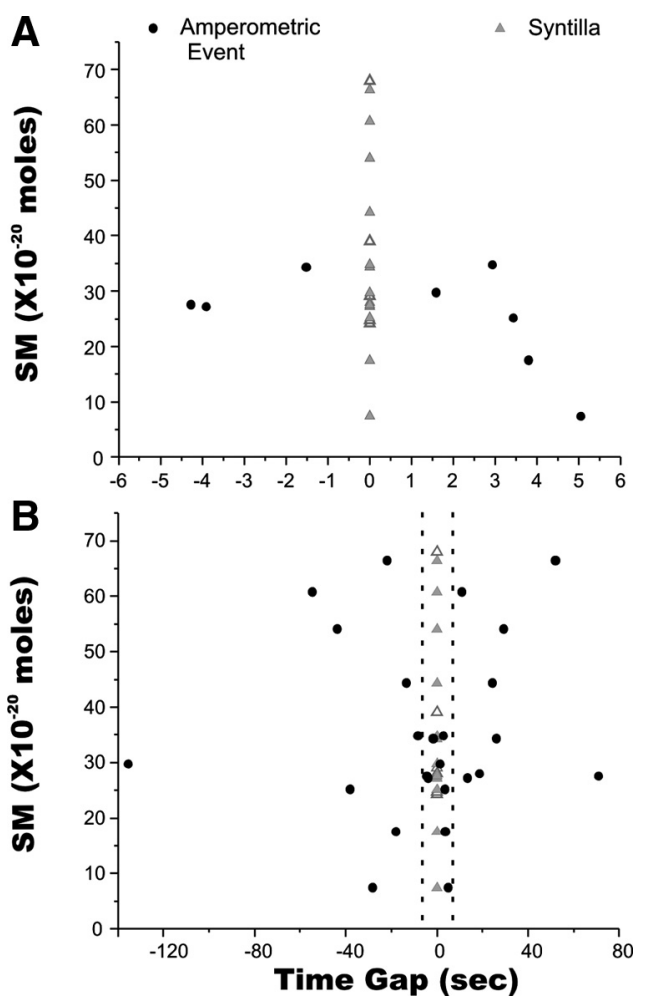

Figure 4. There is no temporal correlation between syntillas and spontaneous release events. Syntillas observed occurring in the region of the terminal where a CFE electrode had been placed were plotted based on their signal mass (SM). Filled triangles represent syntillas occurring near the CFE where long duration amperometric recording was performed before and after the syntilla. For these syntillas, the closest spontaneous amperometric events occurring both before and after the syntilla (black circles) have been plotted. Hollow triangles represent syntillas where amperometric recording was performed only during $\mathrm{Ca}^{2+}$ imaging. $A$, Plot of syntillas versus amperometric events shows that there is no apparent temporal correlation on the scale predicted be required if syntillas were directly responsible for eliciting exocytosis (see Results). $\boldsymbol{B}$, Expanding the time span of the previous graph to include the nearest preceding and following amperometric event (filled triangles only) still does not provide any evidence of temporal correlation.

Another possible scenario is that spontaneous exocytotic events could trigger syntillas. To determine if this was the case, we observed a number of spontaneous release events in false transmitter-loaded terminals during $\mathrm{Ca}^{2+}$ imaging $(n=16)$. Figure 5 shows a representative example of this. Here, a spontaneous release event was observed amperometrically, with no associated intracellular $\mathrm{Ca}^{2+}$ release, during a $4 \mathrm{~s} \mathrm{Ca}^{2+}$-imaging period. In no case did observed spontaneous release events show any evidence of correlation with syntillas. Figure $4 B$ illustrates that this is also the case on a larger time span, as no association was observed between syntillas and the spontaneous amperometric events immediately preceding them. Spontaneous release events were observed an average of $20.26 \pm 5.40$ s preceding syntillas, with the closest occurring $1.59 \mathrm{~s}$ before.

\section{Discussion}

Here, we describe a method to adapt amperometric detection to peptidergic nerve terminals, allowing observation of quantal exocytotic events at the single-terminal level. Development of a means to follow exocytosis at this level has allowed us to directly address the previously unanswerable question as to the involvement of syntillas in spontaneous exocytosis. By simultaneously recording both individual syntillas and spontaneous exocytotic events, we found no evidence for a direct correlation between the two phenomena (Fig. 4).
In most cells, high concentrations of endogenous $\mathrm{Ca}^{2+}$ buffers in the cytosol result in very tight control of $\left[\mathrm{Ca}^{2+}\right]_{i}$. Quantitative modeling has shown that $\mathrm{Ca}^{2+}$ influx through VGCCs results in discrete peaks of $\mathrm{Ca}^{2+}$, or "microdomains," in the immediate vicinity of these channels (Simon and Llinás, 1985). Spatiotemporal modeling of syntillas in NHT by De Crescenzo et al. (2004) has shown that an average syntilla ( $\sim 250,000 \mathrm{Ca}$ ions) occurring at the plasma membrane will raise intracellular $\mathrm{Ca}^{2+}$ to $10 \mu \mathrm{M}$, the concentration believed to be required for neuropeptide secretion (Lee et al., 1992), $500 \mathrm{~nm}$ from the site of release. This effective distance is reduced as the source of the syntillas is moved away from the plasma membrane. Therefore, the fact that syntillas are not capable of directly eliciting spontaneous exocytotic events leads us to theorize that the $\mathrm{Ca}^{2+}$ released by syntillas must be localized to a microdomain separate from where exocytosis occurs in NHT, similar to what has been described in chromaffin cells (ZhuGe et al., 2006).

One possible reason for the lack of correlation between syntillas and spontaneous release events seen here could be that dopamine loading may cause a shift in the $\mathrm{Ca}^{2+}$ sensitivity of exocytosis. Previous work with false transmitter-loaded PC-12 cells showed a 10-fold increase in the spontaneous fusion rate after DA loading (Kim et al., 2000). In theory, this would actually increase the likelihood of observing an association between syntillas and spontaneous release events. However, this was not the case.

Another possibility is that multiple syntillas may be required to work in concert to elicit an exocytotic event in NHT. Similar $\mathrm{Ca}^{2+}$ release events observed in dorsal root ganglion neuronal somata have been suggested to be involved in secretion, with a spark-secretion-coupling probability of $11.4 \mathrm{Ca}^{2+}$ sparks per exocytotic event (Ouyang et al., 2005). However, such a relationship has not been observed in our system. Only in one instance did we observe multiple syntillas in close proximity to the CFE within several milliseconds of each other, and even in this, case no correlated exocytotic event was detected. Despite this, we still cannot exclude the possibility that multiple syntillas could combine to elicit exocytosis.

If syntillas are not responsible for driving spontaneous neuropeptide release, what could be the physiological role of these $\mathrm{Ca}^{2+}$ release events? Syntillas, which raise $\left[\mathrm{Ca}^{2+}\right]_{\mathrm{i}}$ to supramicromolar concentrations in very small regions as described above, may function in such a manner by acting on $\mathrm{Ca}^{2+}$-sensitive targets in one domain, while leaving targets in another domain unaffected. $\mathrm{Ca}^{2+}$ serves as an integral second messenger in a number of intracellular processes, in addition to its role in triggering exocytosis. For example, in superior cervical ganglion neurons, two distinct types of $\left[\mathrm{Ca}^{2+}\right]_{\mathrm{i}}$ release events have been observed which display different kinetics (Yao et al., 2006). Although the physiological role of these two $\mathrm{Ca}^{2+}$ release events are unknown, the fact that two distinct mechanisms of $\left[\mathrm{Ca}^{2+}\right]_{\mathrm{i}}$ release exist may suggest that $\left[\mathrm{Ca}^{2+}\right]_{\mathrm{i}}$ release has the ability to independently modulate multiple physiological processes in concert.

It has been suggested that the mobilization and recruitment of LDCVs to the plasma membrane is a $\mathrm{Ca}^{2+}$-dependent process (Llinás et al., 1991; Becherer et al., 2003; Shakiryanova et al., 2005; Neher, 2006). Recently at the Drosophila neuromuscular junction, it has been shown that RyR-mediated $\mathrm{Ca}^{2+}$ release, via activation of CaMKII, is sufficient to trigger the mobilization of LDCVs to facilitate exocytosis as well as to capture transiting vesicles in an activity-dependent manner, replenishing vesicular pools (Shakiryanova et al., 2007; Wong et al., 2009). Interestingly, it appears that CaMKII is more sensitive to $\mathrm{Ca}^{2+}$ released from 

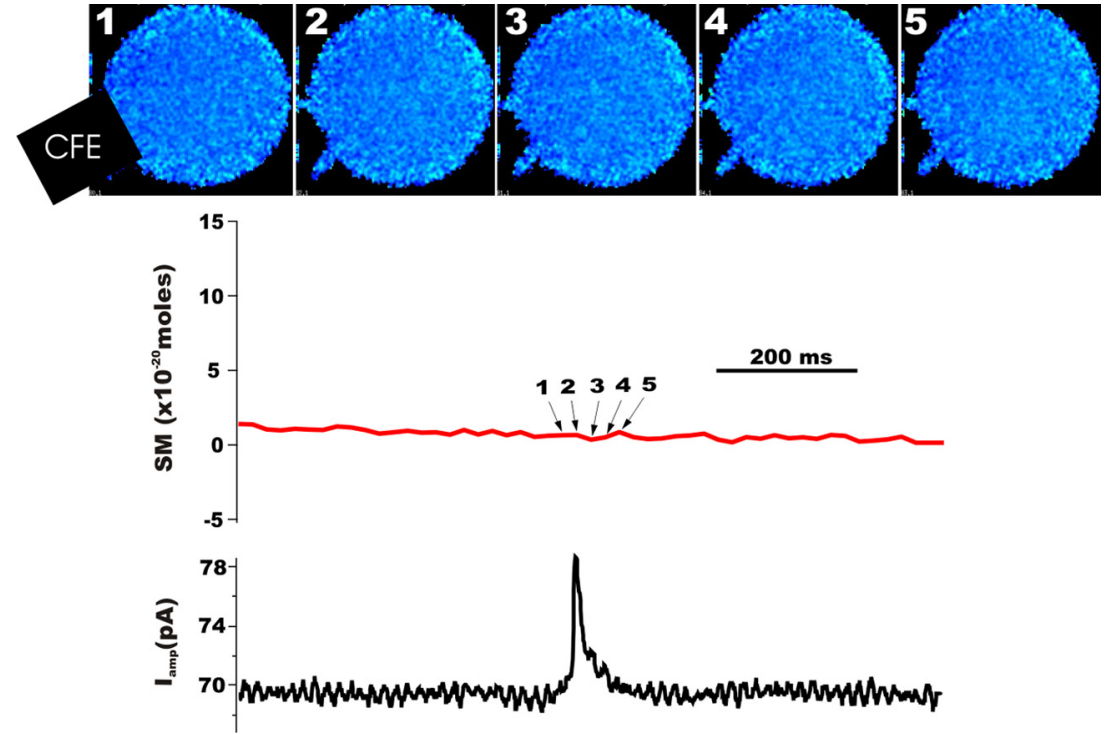

Figure 5. Spontaneous amperometric release events do not trigger calcium syntillas. As in Figure 3, $\mathrm{Ca}^{2+}$ imaging of syntillas and amperometric recording of exocytotic events were performed simultaneously in false transmitter-loaded terminals voltage clamped at $-60 \mathrm{mV}$. Top, Leftmost image shows positioning of CFE relative to a whole-cell patch-clamped terminal. Images 1-5 represent the image frames taken during the occurrence of the spontaneous false transmitter release event. Bottom, Concurrent records of fluorescence in the region of terminal where the (FE was positioned (red trace) and amperometric current (black trace) shows that there are no $\mathrm{Ca}^{2+}$ release events occurring near the CFE when the spontaneous release event is detected. The numbers on the fluorescence trace correspond to the temporal position of the numbered images above.

internal stores than to extracellular $\mathrm{Ca}^{2+}$ (Shakiryanova et al., 2007). This may suggest that the $\mathrm{Ca}^{2+}$ sources for triggering exocytosis and for mobilization of LDCVs are distinct.

More specifically in the case of the NHTs, in the cell bodies and dendrites of magnocellular neurons, intracellular $\mathrm{Ca}^{2+}$ release has already been observed to have a priming effect on neuropeptide secretion (Ludwig and Leng, 2006). Electron microscopy studies have shown that this priming effect involves the relocation of LDCVs closer to the plasma membrane (Tobin et al., 2004). These results suggest that the release of $\mathrm{Ca}^{2+}$ from ryanodine-sensitive stores via syntillas may lead to an increase in the trafficking of LDCVs from reserve pools to the plasma membrane, thereby increasing the size of the readily releasable pool in NHTs.

Conversely, syntillas could also divert LDCVs to a nonreleasable pool as in the chromaffin cells. Jung et al. (2009) has recently showed that localized rises in intracellular $\mathrm{Ca}^{2+}$ are capable of controlling secretory vesicle movement by polymerizing F-actin, freezing them (perhaps by trapping them) so that they cannot move and be exocytosed. Coupled with the voltage dependence of syntillas (De Crescenzo et al., 2006), the above evidence suggests that syntillas could provide an activity-dependent mechanism capable of modulating the availability of secretory vesicles for secretion.

An additional possibility is that ryanodine-sensitive $\mathrm{Ca}^{2+}$ release in NHT may be important specifically for evoked neurotransmitter release. It has been suggested in some systems that distinct vesicular pools are involved in spontaneous versus elicited neurotransmitter release (Sara et al., 2005). Thus, syntillas could indirectly enhance depolarization-induced $\mathrm{Ca}^{2+}$ signals by increasing the basal level of cytosolic $\mathrm{Ca}^{2+}$ concentration at sites only where evoked exocytosis occurs, resulting in an increased probability of release during stimulation. As demonstrated by Galante and Marty (2003), ryanodine-sensitive $\mathrm{Ca}^{2+}$ stores appear to play such a role in evoked neurotransmitter release at the basket cell-pyramidal cell synapse.
Although syntillas do not appear to be directly involved in eliciting spontaneous neuropeptide release, our findings leave open the possibility that they serve a modulatory role in evoked release. The localization of syntillas to distinct microdomains separate from the sites of exocytosis yields further conformation of the exquisite control of $\left[\mathrm{Ca}^{2+}\right]_{i}$ in intracellular environments, allowing this second messenger to control multiple processes independent of one another. Syntillas may prove to be a factor in mobilizing or priming vesicles for release. Although further investigation is required to address this hypothesis, such a process could represent a functional mechanism for plasticity in NHT and, perhaps, other CNS terminals.

\section{References}

Becherer U, Moser T, Stühmer W, Oheim M (2003) Calcium regulates exocytosis at the level of single vesicles. Nat Neurosci 6:846-853.

Berridge MJ (2006) Calcium microdomains: organization and function. Cell Calcium 40:405-412

Cazalis M, Dayanithi G, Nordmann JJ (1987) Hormone release from isolated nerve endings of the rat neurohypophysis. J Physiol 390:55-70.

Chen P, Gillis KD (2000) The noise of membrane capacitance measurements in the whole-cell recording configuration. Biophys J 79:2162-2170.

Chow RH, von Rüden L, Neher E (1992) Delay in vesicle fusion revealed by electrochemical monitoring of single secretory events in adrenal chromaffin cells. Nature 356:60-63.

Chow RH, Klingauf J, Heinemann C, Zucker RS, Neher E (1996) Mechanisms determining the time course of secretion in neuroendocrine cells. Neuron 16:369-376.

Dan Y, Song HJ, Poo MM (1994) Evoked neuronal secretion of false transmitters. Neuron 13:909-917.

De Crescenzo V, ZhuGe R, Velázquez-Marrero C, Lifshitz LM, Custer E, Carmichael J, Lai FA, Tuft RA, Fogarty KE, Lemos JR, Walsh JV Jr (2004) $\mathrm{Ca}^{2+}$ syntillas, miniature $\mathrm{Ca}^{2+}$ release events in terminals of hypothalamic neurons, are increased in frequency by depolarization in the absence of $\mathrm{Ca}^{2+}$ influx. J Neurosci 24:1226-1235.

De Crescenzo V, Fogarty KE, Zhuge R, Tuft RA, Lifshitz LM, Carmichael J, Bellvé KD, Baker SP, Zissimopoulos S, Lai FA, Lemos JR, Walsh JV Jr (2006) Dihydropyridine receptors and type 1 ryanodine receptors constitute the molecular machinery for voltage-induced $\mathrm{Ca}^{2+}$ release in nerve terminals. J Neurosci 26:7565-7574.

Emptage NJ, Reid CA, Fine A (2001) Calcium stores in hippocampal synaptic boutons mediate short-term plasticity, store-operated $\mathrm{Ca} 2+$ entry, and spontaneous transmitter release. Neuron 29:197-208.

Galante M, Marty A (2003) Presynaptic ryanodine-sensitive calcium stores contribute to evoked neurotransmitter release at the basket cell-Purkinje cell synapse. J Neurosci 23:11229-11234.

Gillis KD (2000) Admittance-based measurement of membrane capacitance using the EPC-9 patch-clamp amplifier. Pflugers Arch 439:655-664.

Heinemann C, Chow RH, Neher E, Zucker RS (1994) Kinetics of the secretory response in bovine chromaffin cells following flash photolysis of caged Ca2 +. Biophys J 67:2546-2557.

Jin D, Liu HX, Hirai H, Torashima T, Nagai T, Lopatina O, Shnayder NA, Yamada K, Noda M, Seike T, Fujita K, Takasawa S, Yokoyama S, Koizumi K, Shiraishi Y, Tanaka S, Hashii M, Yoshihara T, Higashida K, Islam MS, et al. (2007) CD38 is critical for social behaviour by regulating oxytocin secretion. Nature 446:41-45.

Jung SR, Kim MH, Hille B, Koh DS (2009) Control of granule mobility and exocytosis by $\mathrm{Ca}(2+)$-dependent formation of $\mathrm{F}$-actin in pancreatic duct epithelial cells. Traffic 10:392-410.

Katz B (1969) The release of neurotransmitter substances. Liverpool: Liverpool UP. 
Kim KT, Koh DS, Hille B (2000) Loading of oxidizable transmitters into secretory vesicles permits carbon-fiber amperometry. J Neurosci 20: RC101.

Lee CJ, Dayanithi G, Nordmann JJ, Lemos JR (1992) Possible role during exocytosis of a $\mathrm{Ca}(2+)$-activated channel in neurohypophysial granules. Neuron 8:335-342.

Lindau M, Neher E (1988) Patch-clamp techniques for time-resolved capacitance measurements in single cells. Pflugers Arch 411:137-146.

Llano I, González J, Caputo C, Lai FA, Blayney LM, Tan YP, Marty A (2000) Presynaptic calcium stores underlie large-amplitude miniature IPSCs and spontaneous calcium transients. Nat Neurosci 3:1256-1265.

Llinás R, Gruner JA, Sugimori M, McGuinness TL, Greengard P (1991) Regulation by synapsin I and $\mathrm{Ca}(2+)$-calmodulin-dependent protein kinase II of the transmitter release in squid giant synapse. J Physiol 436:257-282.

Ludwig M, Leng G (2006) Dendritic peptide release and peptide-dependent behaviours. Nat Rev Neurosci 7:126-136.

Narita K, Akita T, Osanai M, Shirasaki T, Kijima H, Kuba K (1998) A Ca2 +induced $\mathrm{Ca} 2+$ release mechanism involved in asynchronous exocytosis at frog motor nerve terminals. J Gen Physiol 112:593-609.

Narita K, Akita T, Hachisuka J, Huang S, Ochi K, Kuba K (2000) Functional coupling of $\mathrm{Ca}(2+)$ channels to ryanodine receptors at presynaptic terminals. Amplification of exocytosis and plasticity. J Gen Physiol 115:519-532.

Neher E (2006) A comparison between exocytic control mechanisms in adrenal chromaffin cells and a glutamatergic synapse. Pflugers Arch 453:261-268.

Ouyang K, Zheng H, Qin X, Zhang C, Yang D, Wang X, Wu C, Zhou Z, Cheng $\mathrm{H}$ (2005) $\mathrm{Ca} 2+$ sparks and secretion in dorsal root ganglion neurons. Proc Natl Acad Sci U S A 102:12259-12264.

Sara Y, Virmani T, Deák F, Liu X, Kavalali ET (2005) An isolated pool of vesicles recycles at rest and drives spontaneous neurotransmission. Neuron 45:563-573.

Shakiryanova D, Tully A, Hewes RS, Deitcher DL, Levitan ES (2005) Activity-dependent liberation of synaptic neuropeptide vesicles. Nat Neurosci 8:173-178.
Shakiryanova D, Klose MK, Zhou Y, Gu T, Deitcher DL, Atwood HL, Hewes RS, Levitan ES (2007) Presynaptic ryanodine receptor-activated calmodulin kinase II increases vesicle mobility and potentiates neuropeptide release. J Neurosci 27:7799-7806.

Simon SM, Llinás RR (1985) Compartmentalization of the submembrane calcium activity during calcium influx and its significance in transmitter release. Biophys J 48:485-498.

Sun XP, Callamaras N, Marchant JS, Parker I (1998) A continuum of InsP3-mediated elementary Ca2 + signalling events in Xenopus oocytes. J Physiol 509:67-80.

Tobin VA, Hurst G, Norrie L, Dal Rio FP, Bull PM, Ludwig M (2004) Thapsigargin-induced mobilization of dendritic dense-cored vesicles in rat supraoptic neurons. Eur J Neurosci 19:2909-2912.

Wang G, Dayanithi G, Newcomb R, Lemos JR (1999) An R-type Ca ${ }^{2+}$ current in neurohypophysial terminals preferentially regulates oxytocin secretion. J Neurosci 19:9235-9241.

Wong MY, Shakiryanova D, Levitan ES (2009) Presynaptic ryanodine receptor-CamKII signaling is required for activity-dependent capture of transiting vesicles. J Mol Neurosci 37:146-150.

Yao LJ, Wang G, Ou-Yang KF, Wei CL, Wang XH, Wang SR, Yao W, Huang HP, Luo JH, Wu CH, Liu J, Zhou Z, Cheng HP (2006) Ca2+ sparks and $\mathrm{Ca} 2+$ glows in superior cervical ganglion neurons. Acta Pharmacol Sin 27:848-852.

Zhou Z, Misler S (1996) Amperometric detection of quantal secretion from patch-clamped rat pancreatic beta-cells. J Biol Chem 271:270-277.

ZhuGe R, Fogarty KE, Tuft RA, Lifshitz LM, Sayar K, Walsh JV Jr (2000) Dynamics of signaling between $\mathrm{Ca}(2+)$ sparks and $\mathrm{Ca}(2+)$-activated $\mathrm{K}(+)$ channels studied with a novel image-based method for direct intracellular measurement of ryanodine receptor $\mathrm{Ca}(2+)$ current. J Gen Physiol 116:845-864.

ZhuGe R, DeCrescenzo V, Sorrentino V, Lai FA, Tuft RA, Lifshitz LM, Lemos JR, Smith C, Fogarty KE, Walsh JV Jr (2006) Syntillas release Ca2+ at a site different from the microdomain where exocytosis occurs in mouse chromaffin cells. Biophys J 90:2027-2037. 